\title{
Transfer Explanation of Markedness to Learning Difficulty of Preposition Pied Piping in Dative Relative Clause Construction
}

\author{
Jianhong Yang
}

\begin{abstract}
In this study, 262 Chinese-speaking English learners have been randomly sampled as subjects by stratified sampling in terms of their natural groups (i.e., schools, majors or grades) to demonstrate their transformation of dative wh-question into relative clause construction. Based on the acquisition data collected, the conclusive implication is predictably analogous to that of dative wh-question alternation. To elaborate, the marked PS occurs before its unmarked counterpart PPP, which is obviously incompatible with the markedness hypothesis, however, conforming to the syntactically termed economy principle adopted generally to account for an otherwise unexplained phenomenon from a markedness perspective. As far as the structure of the items is concerned, learners tend to take No-prep. strategy (omitting the preposition at all) corresponding to the stimulus sentences categorized under certain type. Thus, the acquisitional sequence in real time is: PS < No-Prep. < PPP. Chi-square test suggests that the difference between the acquisitional sequence and English proficiency level of subjects is significant, so is the difference between the acquisitional sequence and the structure of the stimulus sentences. Furthermore, PPP shares a higher percentage in relative clauses than that in wh-questions, which is accounted for as the influence of topic-command structure, a usual sentence type in Chinese defined as the topic-prominent language. Besides, the markedness status of who and whom also exerts its influence on the acquisitional sequence, which provides the prerequisite for the construction of the processing acquiring mechanism hypothesis. It is suggested in conclusion that items may as well be inputted in the form of routines, rather patterns.
\end{abstract}

Index Terms-Markedness theory, preposition pied piping, processing acquiring mechanism hypothesis, topic-command structure.

\section{INTRODUCTION}

In Prague School phonology where the linguistic concept of markedness originates (Trubetzkoy 1929; Jokobson 1937, cited in Luelsdorff 2004) [1], marked vs. unmarked designated by $[+\mathrm{A}]$ and $[-\mathrm{A}]$ respectively ([A] standing for every possible linguistic feature), is a representational form developed to describe linguistic units on the basis of the presence or absence of the smallest semantically significant features. To elaborate, when two phonemes are distinguished, certain structures are often avoided while others are generated; the avoided structures are called 'marked' while the generated ones are 'unmarked'. For instance, any given segment becomes marked by the addition of features for

Manuscript received January 4, 2018; revised May 25, 2018.

Jianhong Yang is with Tianjin University, Renai College, Tianjin, CO 301636 China (e-mail: tianjinjianhongyang@hotmail.com). voicing, aspiration, nasalization, etc., their unmarked counterparts characterized by the absence of that feature, as reflected in the negative affix: voiceless, unaspirated, non-nasal, etc. In position of consonantal neutralization --e.g., for bilabial stops following word-initial/s/ in English --only the unmarked of the contrasting pair may appear, in this case (voiceless) /p/ (i.e., /b/ [+voiced]; /p/ [-voiced]). Markedness is still an influential concept in current phonological theory. In Optimality Theory, many of the central arguments concerning constraints and ordering have to do with the markedness of a form. Behind the theory are four leading ideas (de Lacy 2006) [2]:

a) Competence markedness

b) Preservation of the marked

c) Markedness conflation

d) Hierarchy conflict

In recent years, researchers have been engaged in the experimental application of linguistic markedness theory to aspects of second language learning because of its great potential for a better explanation and presupposition of second language acquisition. Markedness theory predicts the mastery of specific structures at a particular stage in the acquisition process is reflected through relative degrees of difficulty in producing those structures, which, in turn, suggests that the relative markedness of L1 and L2 features can be used to predict the areas of L2 difficulty and L1 transfer.

Cognitive theory of markedness claims that learners' understanding of the transferability of L1 features is based on their perception of the prototypicality of those features rather than the markedness itself (Ellis 1994) [3]. Unlike the traditional views of markedness (Complexity Principle and Contextual Neutralization ), which assume that it is closely linked to complexity, infrequency, and lack of naturalness, or that it may defined via certain implicational relationships, the learnability approach to markedness, by considering the acquisition situation of L1 learners, is based on the assumption that negative evidence is not reliably available to L1 learners, so it cannot be relied on as a means to remove any incorrect hypotheses made by the child in the course of acquisition; rather, the child must proceed conservatively, starting with restrictive hypotheses that can, if necessary, be disconfirmed on the basis of positive evidence only (Baker 1979; Berwick 1985, cited in White 1987) [4].

\section{MARKEDNESS IDENTIFICATION OF PREPOSITION STRANDING AND PREPOSITION PIED PIPING}


The term "marked" has been defined in many different ways, but underlying all of the definitions is the notion that some linguistic features are "specific" in relation to others, which are more "basic". For instance, the adjectives old and young can be considered unmarked and marked respectively, because (1a) How old is she? analogous to What's her age? can be used to ask a person's age, whereas young can only be used in some very specific sense. (1b) How young is she? implies that Is she as young as she makes out?

(1) a. How old is she?

b. How young is she?

Similar psycho-linguistically marked/complex adjectives are small, short and slow in the following examples. How big/ *small is the house? How long/*short was the movie? How far/*slow does he work? etc.

The use of 'break' in ( $2 \mathrm{a})$ can be considered marked in relation to the use of 'break' in (2b).

(2) a. The cat broke the vase.

b. It takes a graduate trainee one month to break in.

(3a) Hi, how are you? is only a usual greeting which may or may not even be answered. But as for (3b) Hi, how's your Dad? this is special. You are likely to recognize the question as actually asking how your Dad is. It carries the implication that your Dad is not well.

(3) a. Hi, how are you?

b. Hi, how's your Dad?

The following structures present pied piping in relative clauses with indirect objects (4a) or preposition phrases (4b), while $(5 \mathrm{a})$ and $(5 \mathrm{~b})$ preposition stranding.

(4) a. The person for whom Diane baked a cake was Nicole.

b. The teacher helped the student for whom the lesson was difficult.

(5) a. The person who/m Diane baked a cake for was Nicole.

b. The teacher helped the student whom the lesson was difficult for.

Preposition stranding (abbreviated to PS) results when wh-movement occurs, that is, wh-element is separately extracted out of the prepositional phrase (PP) while leaving the preposition behind. By contrast, preposition pied piping (abbreviated to PPP) exhibits that the preposition is fronted along with the moved wh- interrogative pronoun, thus, the whole PP (prepositional phrase) is preposed as an entire constituent.

\section{A. Transfer Explanation of Markedness to Learning Difficulty}

Kellerman (1985) [5] views the relationship of markedness to learning difficulty in a different way. The learner has a "strategy of tranfer" in which markedness, in both L1 and L2, plays the following role:

(a) Where a message (or part of a message) can be equally well expressed by two or more related syntactic structures, the less marked the structure the more likely it will be preferred as the basis for transfer.

(b) Where one lexical structure (such as a word) can represent two or more related meaning (polysemy), the more marked the meaning the more likely the learner is to avoid that lexicon structure.
Markedness for Kellerman therefore has psychological meaning, in that "a structure or meaning will be marked in the $\mathrm{NL}$ if there are related syntactic structures which express the same message in psychologically simpler ways, or meanings of the same word or lexical unit which the native speaker considers more central" (Kellerman 1983: 38, cited in White 1990) [6]. Evidence for Kellerman's strategy of transfer has come about through the positing of three constraints on the language learning process (White 1990).

The first is the learner's perception of the typological 'distance' between native and target languages. If perceived distance is small (e.g., German vis-à-vis Dutch), the leaner will more readily transfer; hence, interference errors will be more numerous. But if perceived distance is large (e.g., L1 and any genetically unrelated L2), the learner will be less inclined to transfer, and interference errors will be fewer.

The second constraint is the learner's perception of markedness of a potentially transferable item in his or her native language. The more marked the item the less likely the transfer. But these constraints work together to produce scalar tendencies of transferability, such that heaviest transfer is predicted for the combination of unmarked items and perceived typological distance.

The third constraint is the nature of the learner's knowledge of the target language. The presence of such knowledge, real or assumed on the part of the learner, will affect transfer in a systematic way.

\section{B. The Experimental Study of Preposition Stranding and Pied Piping}

Following van Riensdijk's identification of pied piping as unmarked and preposition stranding as marked, and translating ease of learning into real time (1978) [7], Mazurkewich (1984a) [8] assumes that the unmarked pied piping would be easy to acquire before the marked preposition stranding, which displays experimentally the prediction made by markedness theory. Mazurkewich used a written question formation test to investigate the acquisition of PS/PPP in wh-questions by learners of English from two unrelated languages backgrounds, French and Inuktitut. The results, however, were ambivalent: the French speakers produced a higher percentage of pied piping constructions, that is, unmarked, than marked stranded constructions, while the opposite was true for the Inuktitut speakers. Besides, as far as the French speakers were concerned, the percentage of both constructions generally increased with the level of competence in English, but the number of cases of preposition stranding never exceeded that of cases of pied piping. Dismissing this obvious counterexample to the hypothesis, Mazurkewich claims that the Inuktitut speakers were more likely to have acquired the marked preposition stranding, which suggested that they were further advanced than the French speakers. The Inuktitut speakers are educated mainly in English and only received instruction in Inuktitut throughout their primary and secondary school years while the French speakers are taught English as a second language and their main education is carried out in French. Mazurkewich concluded that the data bear out the prediction that the unmarked dative question structure pied piping is acquired before the marked one preposition stranding in spite 
of the fact that the unmarked form may only be minimally available to learners in the linguistic environment they are exposed to, thus proved the evidence in support of theory of markedness.

Mazurkewich constructed an explanation in terms of the theory of generative grammar referred to as Government Binding Theory, central to which are the notions of Universal Grammar (UG) and within UG a set of core rules of grammar. Such rules are determined by theory of markedness associated with UG which determines those rules that are core rules are unmarked and those rules that are peripheral marked. She elaborated that this order of difficulty reflects an aspect of Universal Grammar (UG): pied piping are part of core grammar and therefore unmarked in UG, while stranded constructions are peripheral and therefore marked in UG, and markedness as defined by UG directly explains the order of difficulty: constructions that are deemed marked in UG are more difficult for L2 learners to acquire than unmarked constructions.

Furthermore, Mazurkewich proposes a development sequence of the application of the general movement rule Move $\alpha$. She claims that Move $\alpha$ is applied across-the-board once acquired: the rule would first apply to the preposition phrase in (6a) (the underlying structure of both (6b) and (6c)) to derive (6b), which is held to be the unmarked form and at a later stage, it would apply to just the wh-pronoun to derive (6c) once stranding is learned.

(6) a. Diane baked a cake for whom? (Underlying Structure)

b. For whom did Diane bake a cake? (Pied Piping)

c. Who/m did Diane bake a cake for? (Preposition Stranding

Mazurkewich's arguments are dismissed by both Kellerman (1985) and White (1987), both of them prefer to L1 transfer explanation, because Inuktitut does not have preposition and so, arguably, transfer is not an issue, whereas French (especially standard French) has pied piping analogous to that in English, therefore, French learners are more likely to be influenced by the interference from their maternal language, thus may have transferred their L1 structure. Mazurkewich (1985) [9], however, discounted L1 transfer as an influence on acquisition order and the ease of acquisition, providing more evidence that non-standard forms which manifest preposition stranding also appear in Quebec French as shown in examples reported by Vinet (1979) [10].

(7) a. le boss que je travaille pour

'the boss that I work for'

b. le gars que j'ai sorti avec

'the gay that I went out with'

Vinet (1979) reported that preposition stranding occurs only in restricted cases involving some prepositions in French (especially in Quebec French) as in 5a and 5b.

Although Allen (1980) [11] maintains these constructions do not result from preposition stranding but from the fact that these prepositions are intransitive, Mazurkewich (1985) takes them to be the product of preposition stranding. Thus, she claims that French learners have equal access to both stranding and pied piping which is considered extremely dubious by Bardovi-Harlig (1987) [12] in light of the investigation that stranding constructions, in Quebec French, are restricted to certain prepositions, as shown in examples (7a) and (7b), and to certain sentence type (i.e., declarative), as shown by examples (8a) and (8b) in which stranding in questions is ungrammatical (Allen, 1980).

(8) a. * Qui sors-tu avec?

b. * Qui tu sors avec?

'Who are you going out with?'

Accordingly, Bardovi-Harlig suggests that the practical investigation to eliminate the possible influence of transfer in markedness studies is to examine acquisition by subjects whose first languages does not prefer, or if possible, even possess, exactly the construction which is claimed to be unmarked in Universal Grammar. She further replicated Mazurkewich's test for dative wh-questions (linguistically simple) and extended the elicitation task to include relative clauses (linguistically more complex). Her expanded test was administered to a group of subjects with mixed language backgrounds, among which each allowed only the unmarked pied piping. She restates the markedness hypothesis as follows: "unmarked structures are acquired before marked structures, all things being equal" (Bardovi-Harlig 1987: 402).

\section{EXPERIMENT}

\section{A. The Experimental Subjects}

The stratified sampling, instead of the random procedure for selecting subjects, has been conducted with attempt to present the generalizable hierarchy of the results reported in the study. The 262 English learners stratified according to their natural groups (i.e., universities, majors and grades) were divided into four proficiency levels: level 1 (primary), level 2 (low-intermediate), level 3 (high-intermediate) and level 4 (advanced). Level 1 (primary) is made up of 78 teenagers from Grade 2, No.42 Senior High School, key middle school of Hexi distract, Tianjin. Level 2 (lowintermediate) includes 59 non-English major sophomores (28 from Department of Civil Engineering and 31 from Department of Chemistry, Tianjin University, Renai College). Level 3 (high-intermediate) is composed of 72 English-major students (27 freshmen, 24 sophomores and 21 juniors from Foreign Languages College, Tianjin Normal University. And the remaining 53 subjects identified as level 4 in proficiency were English-major graduate students in School of Foreign Languages and Literature, Tianjin University. The test originally started out with subdividing them in different levels, because it had been assumed that there existed discrepancy among grades. However, owning to the small size of English-major classes and to no significant differences in the responses of the 72 subjects to the test concerned when taken separately, here no subdivision was committed. The sample is large, readily available and representative.

\section{B. The Experimental Materails}

The linguistic manipulation task reexamines BardoviHarlig's (1987) study in order to examine the relative clauses constructions derived by wh-movement. 
In order to ensure particular distribution of data obtained in such tests really reflect the linguistic knowledge of L2 learners, the subjects were instructed to use who, whom, or which, to introduce the relative clauses in which overt wh-relativizers allow pied piping as well as preposition stranding, as the following example (9a) and (9b) show. Relative clauses with no overt wh-element, rather introduced by that or $\varnothing$, which are well-formed and grammatical iff the preposition is stranded, as in example (9c) and (9d), are not involved in the test.

As in the first part of the test, an example (10) which does not require a preposition was provided.

(9) a. The man to whom Lucy gave the book was Kevin.

b. The man whom Lucy gave the book to was Kevin.

c. The man that/ $\varnothing$ Lucy gave the book to was Kevin.

d. *The man to that/ $\varnothing$ whom Lucy gave the book was Kevin.

(10) Mary saw the man

(The man had stolen her purse)

Mary saw the man who had stolen her purse.

The stimulus sentences contain five to- dative verbs which allow the dative alternation (lend, throw, read, give, send). In conformity with the first part, five sentences with each form, without a preposition and with one, were identified as Type 1 and Type 2 respectively. Also included are five verbs (labeled Type 3) which must occur with a preposition: paid (for), ask (for), report (to), complain (about) and the predicate be different (for). There are also six sentences (labeled Type 4) with verb-particle combinations (look up, call up, clear out, blow around, burn down, throw away) to test for overgeneralization of pied piping since particles can not be preposed as shown in (11). Finally, four distractors included were labeled Type 4. Among them, two sentences concern the relativizer who/which playing as the subject in the relative clauses and two deal with the relativizer who/which as the direct object. The 25 items were presented in random order.

(11) a. Bill wrote down the information which he had looked up. looked.

b. *Bill wrote down the information up which he had

Similarly, the classification can be depicted as follows:

Type 1: NP' + NP (representing the structure of the sentences being relativized in the parentheses)

(12) The man was Kevin.

(Lucy gave the man the book)

Type 2: NP + PP [P + NP']

(13) The man was Kevin.

(Lucy gave the book to the man)

Type 3: NP ++ PP [P + NP']

(14) a. The clerk was fired.

(Bill had complained about the clerk)

b. The teacher helped the student

(The lesson was difficult for the student)

Type 4: NP (distractors)

(15) a. Bill wrote down the information

b. The desk

(He had looked up the information) belongs to my grandfather.
(We just cleaned out the desk)
c. Crystal Palace is a famous

hotel

(The hotel hosts many conventions)

d. The manager hired the

student

(The teacher had recommended the student)

Chinese written instructions were given "Relativizing the sentences in the parentheses using who, whom, or which". The instructions were also read to the subjects by the classroom instructors and any questions about the instructions were allowed to be answered. The subjects in Level 1 were given 35-40 minutes to complete the task, those in Level 2 and Level 3 20-25 minutes and those in Level 4 were allowed to work at their own pace (most took between 10-15 minutes).

\section{Classification of Responses}

The responses obtained in this testing were classified into four categories required to best characterize them for analysis. The difference between responses manifesting PS and PPP in terms of responses is significant $(\mathrm{X} 2(20,14410)=$ $21728.295, p<0.05$ ), which is tabulated in Table $\mathrm{I}$.

T ABLE I: RELATIVIZER (WHO/M) DISTRIBUTION IN TERMS OF RESPONSES

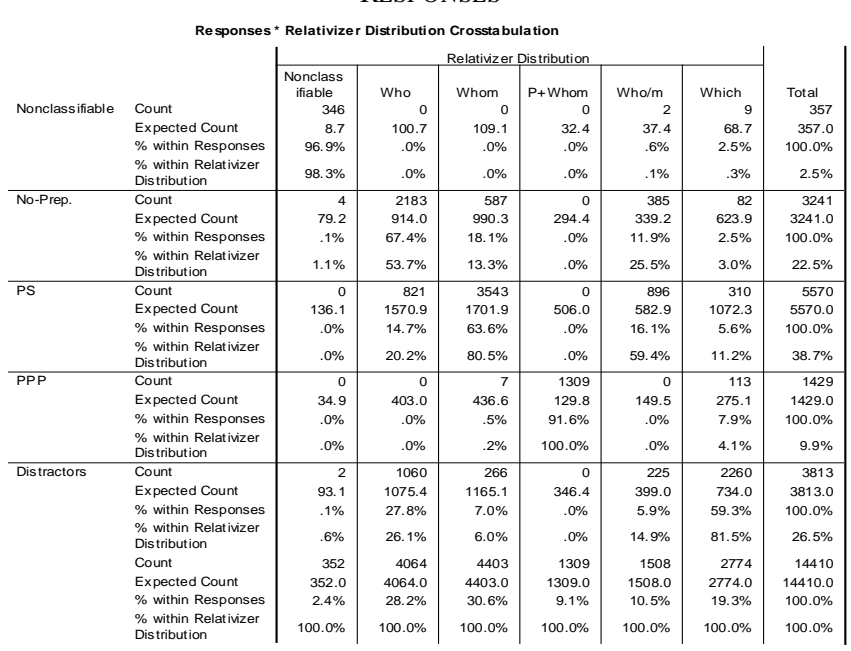

0 cells $(.0 \%)$ have expected count less than 5 . The minimum expected count is 8.72 .

$\mathrm{X} 2(20,14410)=21728.295, p<0.05$

The categories are defined as follows:

Preposition pied piping (PPP) refers to the responses in which the preposition was pied piped along with the wh-word, as in (16):

(16) a. The man to whom Lucy gave the book was Kevin.

b. The teacher helped the student for whom the lesson was difficult.

Preposition stranding (PS) refers to the responses in which the preposition was stranded at the end, as in (14):

(17) a. The man whom Lucy gave the book to was Kevin.

b. The teacher helped the student whom the lesson was difficult for.

No-preposition (No-Prep.) refers to the responses in which the preposition was omitted, as in (15):

(18) *a. The person whom Allen lent $\$ 100$ was Louise.

*b. The teacher helped the student whom the lesson 
was difficult.

Nonclassifiable refers to the responses which did not fall into any of the above categories. The most common examples of this category occurred in part II are responses in which it is usually the subject that was relativized, as in (16):

(19) a. The artist painted a picture for which he sold $\$ 3,000.00$.

(He sold the picture for $\$ 3,000.00$ )

b. The person_who was lent $\$ 100$ to by Allen was Louise.

(Allen lent the person \$100)

c. * The person who lent $\$ 100$ was Louise.

(Allen lent the person \$100)

\section{Hypothesis and the Experimental Procedure}

The numerical value of Chi-square $\mathrm{x} 2$ can be viewed as the degree to which observed sample frequencies differ from expected population frequencies. The statistical hypothesis is:

$$
\mathrm{H} 0: \mathrm{fO}=\mathrm{fE}
$$

\section{$\mathrm{H} 1: \mathrm{fO} \neq \mathrm{fE}$}

The null hypothesis is usually abbreviated to H0 while the alternative hypothesis to $\mathrm{H} 1$. And fO represents the observed frequency while $\mathrm{fE}$ the expected frequencies.

The central question underlying the statistics is whether the observed frequencies for the different categories within the variables related to are independent. To test this question, the following research hypothesis could be formulated.

H0: The observed frequency for PS/PPP and the proficiency level of the subjects are independent.

H1: The observed frequency for PS/PPP and the proficiency level of the subjects are related.

Thinking along these lines, it can also be hypothesized:

H0: The observed frequency for PS/PPP and the type of the stimulus sentences in the test are independent

H1: The observed frequency for PS/PPP and the type of the stimulus sentences in the test are related.

The focus of the study is on the null hypothesis, if it cannot rejected, the research should conclude that the subjects' responses have no relationship other than chance with what level they are identified. if the null hypothesis is rejected and the alternative hypothesis is accepted, there is probably a relationship between the variables within a certain probability -99 percent at the conservative $a<.01$ or at the more liberal $a<.05$ in the study.

\section{E. Statistical Analysis of Results}

0 cells $(.0 \%)$ have expected count less than 5 . The minimum expected count is 64.00 .

\section{$\mathrm{X} 2(15,14410)=9331.723, \mathrm{p}<0.05$}

A number of $\mathrm{x} 2$ analyses were performed comparing the responses of each group to relative clauses. $\mathrm{H} 0$ is rejected at $\mathrm{p}$. $<05$, thereby $\mathrm{H} 1$ is accepted. In other words, the difference between responses manifesting PS and PPP in terms of types of the stimulus sentences is significant $(\mathrm{X} 2(15,14410)=$ $9331.723, \mathrm{p}<0.05)$, so is that in terms of the proficiency level of the subjects in the test $(X 2(15,14410)=3690.763$, p $<0.05)$, which are tabulated in Table 2 and Table III respectively.
The frequency and percentages of the total responses calculated individually for the four levels of the experimental groups indicate clearly that Chinese-speaking English learners master the marked PS of dative forms first while the unmarked PPP later. Thus, the acquisition difficulty and the relative productivity of dative relative clause construction fall out the prediction made by the Markedness theory. Of prime interest is that such an acquisitional sequence is more salient in the data obtained from subjects at Level 1 and Level 2 who consistently shared higher percentages of PS as compared with PPP.

TABLE II: RELATIVIZER (WHO/M) DISTRIBUTION IN TERMS OF T YPES

\begin{tabular}{|c|c|c|c|c|c|c|c|c|}
\hline & & \multicolumn{6}{|c|}{ Relativizer Distribution } & \multirow[b]{2}{*}{ Total } \\
\hline & & $\begin{array}{c}\text { Nonclass } \\
\text { ifiable }\end{array}$ & Who & Whom & P+Whom & who/m & Which & \\
\hline \multirow[t]{4}{*}{ Type1 } & Count & 77 & 2286 & 820 & 243 & 504 & 0 & 3930 \\
\hline & Expected Count & 96.0 & 1108.4 & 1200.8 & 357.0 & 411.3 & 756.5 & 3930.0 \\
\hline & $\%$ within Type & $2.0 \%$ & $58.2 \%$ & $20.9 \%$ & $6.2 \%$ & $12.8 \%$ & $.0 \%$ & $100.0 \%$ \\
\hline & $\begin{array}{l}\text { \% within Relativizer } \\
\text { Distribution }\end{array}$ & $21.9 \%$ & $56.3 \%$ & $18.6 \%$ & $18.6 \%$ & $33.4 \%$ & $.0 \%$ & $27.3 \%$ \\
\hline \multirow[t]{4}{*}{ Type2 } & Count & 50 & 488 & 2224 & 716 & 452 & 0 & 3930 \\
\hline & Expected Count & 96.0 & 1108.4 & 1200.8 & 357.0 & 411.3 & 756.5 & 3930.0 \\
\hline & $\%$ within Type & $1.3 \%$ & $12.4 \%$ & $56.6 \%$ & $18.2 \%$ & $11.5 \%$ & $.0 \%$ & $100.0 \%$ \\
\hline & $\begin{array}{l}\text { \% within Relativizer } \\
\text { Distribution }\end{array}$ & $14.2 \%$ & $12.0 \%$ & $50.5 \%$ & $54.7 \%$ & $30.0 \%$ & $.0 \%$ & $27.3 \%$ \\
\hline \multirow[t]{4}{*}{$\begin{array}{l}\text { Type3 } \\
\end{array}$} & Count & 119 & 230 & 1093 & 350 & 327 & 501 & 2620 \\
\hline & Expected Count & 64.0 & 738.9 & 800.5 & 238.0 & 274.2 & 504.4 & 2620.0 \\
\hline & $\%$ within Type & $4.5 \%$ & $8.8 \%$ & $41.7 \%$ & $13.4 \%$ & $12.5 \%$ & $19.1 \%$ & $100.0 \%$ \\
\hline & $\begin{array}{l}\text { \% within Relativizer } \\
\text { Distribution }\end{array}$ & $33.8 \%$ & $5.7 \%$ & $24.8 \%$ & $26.7 \%$ & $21.7 \%$ & $18.1 \%$ & $18.2 \%$ \\
\hline \multirow[t]{8}{*}{ Type4 } & Count & 106 & 1060 & 266 & 0 & 225 & 2273 & 3930 \\
\hline & Expected Count & 96.0 & 1108.4 & 1200.8 & 357.0 & 411.3 & 756.5 & 3930.0 \\
\hline & $\%$ within Type & $2.7 \%$ & $27.0 \%$ & $6.8 \%$ & $.0 \%$ & $5.7 \%$ & $57.8 \%$ & $100.0 \%$ \\
\hline & $\begin{array}{l}\% \text { within Relativizer } \\
\text { Distribution }\end{array}$ & $30.1 \%$ & $26.1 \%$ & $6.0 \%$ & $.0 \%$ & $14.9 \%$ & $81.9 \%$ & $27.3 \%$ \\
\hline & Count & 352 & 4064 & 4403 & 1309 & 1508 & 2774 & 14410 \\
\hline & Expected Count & 352.0 & 4064.0 & 4403.0 & 1309.0 & 1508.0 & 2774.0 & 14410.0 \\
\hline & $\%$ within Type & $2.4 \%$ & $28.2 \%$ & $30.6 \%$ & $9.1 \%$ & $10.5 \%$ & $19.3 \%$ & $100.0 \%$ \\
\hline & $\begin{array}{l}\text { \% within Relativizer } \\
\text { Distribution }\end{array}$ & $100.0 \%$ & $100.0 \%$ & $100.0 \%$ & $100.0 \%$ & $100.0 \%$ & $100.0 \%$ & $100.0 \%$ \\
\hline
\end{tabular}

T ABLE III: RELATIVIZER (WHO/M) DISTRIBUTION IN TERMS OF PROFICIENCY Levels

\begin{tabular}{|c|c|c|c|c|c|c|c|c|}
\hline & & vel & & Cro & ation & & & \\
\hline & & & & Relativizer & stribution & & & \\
\hline & & $\begin{array}{l}\text { Nonclass } \\
\text { ifiable }\end{array}$ & Who & Whom & P+Whom & who/m & Which & Total \\
\hline Level1 & Count & & 1692 & 1396 & & & & 4290 \\
\hline & Expected Count & 104.8 & 1209.9 & 1310.8 & 389.7 & 448.9 & 825.8 & 4290.0 \\
\hline & $\%$ within Level & $6.5 \%$ & $39.4 \%$ & $32.5 \%$ & $1.0 \%$ & $2.5 \%$ & $18.0 \%$ & $100.0 \%$ \\
\hline & $\begin{array}{l}\% \text { within Relativizer } \\
\text { Distribution }\end{array}$ & $79.0 \%$ & $41.6 \%$ & $31.7 \%$ & $3.2 \%$ & $7.2 \%$ & $27.9 \%$ & $29.8 \%$ \\
\hline Level2 & Count & 63 & 1070 & 1161 & 103 & 215 & 633 & 3245 \\
\hline & Expected Count & 79.3 & 915.2 & 991.5 & 294.8 & 339.6 & 624.7 & 3245.0 \\
\hline & $\%$ within Level & $1.9 \%$ & $33.0 \%$ & $35.8 \%$ & $3.2 \%$ & $6.6 \%$ & $19.5 \%$ & $100.0 \%$ \\
\hline & $\begin{array}{l}\% \text { within Relativizer } \\
\text { Distribution }\end{array}$ & $17.9 \%$ & $26.3 \%$ & $26.4 \%$ & $7.9 \%$ & $14.3 \%$ & $22.8 \%$ & $22.5 \%$ \\
\hline Level3 & Count & 5 & 891 & 1461 & 381 & 433 & 789 & 3960 \\
\hline & Expected Count & 96.7 & 1116.8 & 1210.0 & 359.7 & 414.4 & 762.3 & 3960.0 \\
\hline & $\%$ within Level & $.1 \%$ & $22.5 \%$ & $36.9 \%$ & $9.6 \%$ & $10.9 \%$ & $19.9 \%$ & $100.0 \%$ \\
\hline & $\begin{array}{l}\text { \% within Relativizer } \\
\text { Distribution }\end{array}$ & $1.4 \%$ & $21.9 \%$ & $33.2 \%$ & $29.1 \%$ & $28.7 \%$ & $28.4 \%$ & $27.5 \%$ \\
\hline $\begin{array}{l}\text { Level4 } \\
\end{array}$ & Count & 6 & 411 & 385 & 783 & 751 & 579 & 2915 \\
\hline & Expected Count & 71.2 & 822.1 & 890.7 & 264.8 & 305.1 & 561.2 & 2915.0 \\
\hline & $\%$ within Level & $.2 \%$ & $14.1 \%$ & $13.2 \%$ & $26.9 \%$ & $25.8 \%$ & $19.9 \%$ & $100.0 \%$ \\
\hline & $\begin{array}{l}\text { \% within Relativizer } \\
\text { Distribution }\end{array}$ & $1.7 \%$ & $10.1 \%$ & $8.7 \%$ & $59.8 \%$ & $49.8 \%$ & $20.9 \%$ & $20.2 \%$ \\
\hline & Count & 352 & 4064 & 4403 & 1309 & 1508 & 2774 & 14410 \\
\hline & Expected Count & 352.0 & 4064.0 & 4403.0 & 1309.0 & 1508.0 & 2774.0 & 14410.0 \\
\hline & $\%$ within Level & $2.4 \%$ & $28.2 \%$ & $30.6 \%$ & $9.1 \%$ & $10.5 \%$ & $19.3 \%$ & $100.0 \%$ \\
\hline & $\begin{array}{l}\text { \% within Relativizer } \\
\text { Distribution }\end{array}$ & $100.0 \%$ & $100.0 \%$ & $100.0 \%$ & $100.0 \%$ & $100.0 \%$ & $100.0 \%$ & $100.0 \%$ \\
\hline
\end{tabular}

0 cells $(.0 \%)$ have expected count less than 5 . The minimum expected count is 71.21 .

$\mathrm{X} 2(15,14410)=3690.763, p<0.05$

\section{Topic Prominence in PPP Relative Clause}

The clauses contained in the test of this study are identified as defining relative clauses in which clauses come immediately after its preceding nouns/pronouns. Due to topicalization mechanism adopted by Chinese-speaking English learners more specifically, PPP shares higher percentage in relative clauses comparing with that in 
wh-questions.

There is detailed evidence for the heavy reliance of some learners on Topic-Comment Patterning in the early stages of acquisition (Odlin 1989: 89, cited in Ellis 1994; Adani, 2010) [13], [14]. Richards (2005) [15] defines a topic- prominent language in terms of its differentiated characteristics from a subject-prominent language

A language in which the grammatical units of topic and comment are basic to the structure of sentences is known as a topic-prominent language. Chinese is a topic-prominent language, since sentences with topic-comment structure are a usual sentence type in Chinese. For example:

Zhangsan wo yijing jian guo le

Zhangsan I already see aspect partical marker

Zhangsan, I have already seen (him).

(Topic) (Comment)

The observable characteristic of Chinese language governed by the topic-comment structure suggests that Chinese-speaking English learners intend to employ the discourse strategy, that is, to learn a particular target language form and then hypothesize that the form is used to express a particular discourse function. Thus, the linguistic material must be re-ordered and rearranged when mapping semantics and surface form (Franco 2012; Ning 2013) [16], [17]. Topic prominence necessitates learners' preference for certain linguistic form (Lin 2014; Vasishth 2013; Wu 2012) [18]-[20]. Accordingly, PPP manifesting essentially the minimal distance between the preposition and the preceding noun may present maximum salience for the noun functioning as a topic (illustrated in the following figure).

(20) topic [The man] to whom Lucy gave the book was Kevin.

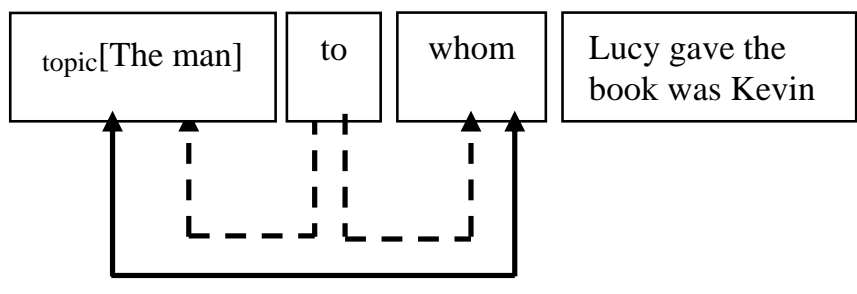

Fig. 1. Topic prominence in PPP relative clause.

\section{CONCLUSION}

\section{A. Limitations of the Study}

It is important to broaden the range of data beyond that considered in this study. It was felt that such a data was too small for the investigation of the dative alternation, and that only if a reasonably large sample of verbs in dative-type constructions was considered could a reasonable proposal about the manner of the acquisition of the construction be advanced.

The technique adopted for data collection in this research is the test only, which has its own strengths and unfortunately suffers weakness as well. "In general terms, a test is a systematic method of eliciting performance which is intended to be the basis for some sort of decision making, although this does not deny that many tests are not terribly systematic, elicit fairly questionable language performance, and do not lead to any decision being made" (Skehan 1998) [21]. Tests are often limited by research facilities and other problems. The present study is no exception.

Initially, it is hard to imagine how to control all variables in one test or to control one variable in all tests involved, the tester could only manage to control those topical and situational variables. Other variables such as physical conditions, mood of the subjects, etc., were not taken into account in the analysis. Second, psychological factors are changeable, which, in practice, cannot be possibly considered in one simple test. For instance, the tester can not possibly hold a situation for a long time, it may change its contents as the time passes on. And also, the emotions and attitudes of the tester may influence the testees to some extent. Besides, it is impossible for a student tester to have access to a wide range of evidence about the performance of the testees. Such being the case, the only practical possibility in the present research was to control some of more important variables and ignore the rest. A more formal testing approach represents a belief in efficiency of sampling through systematic data collection, so that generalizations can be made to a wide range of contexts going well beyond the test itself.

Another limitation which should be mentioned here is the method of measurement. Some more advanced technology should be desirable in future research.

In short, considering the above limitations, the findings of this study are not carved in stone. It is only a trial study. The results obtained in the present research are tentative - open to challenge and verification. Multiple techniques are needed whenever time and resources are available to obtain more overall and accurate results.

\section{B. Pedagogic Suggestions for EFL Classroom Interaction}

Relative clause modifying an noun or noun phrase, presents its syntactic function as adjective, is subordinate to the principal clause, which can supply more information in detail.

With respect to dative relative clauses, both Chinese and English follow the syntactic rule of adjacency to the head noun, but the similarity ends there. There are prominent differences between them. First, Chinese relative clause, characterized by a left-branching structure which is usually indicated by the relative particle "de", is analogous to other adjectival phrases which are head-final (i.e., pre-nominal, modifiers virtually always precede the noun that they modify). On the contrary, English relative clause, fully head-initial (post- nominal), features right-branching structure introduced by relative pronouns including "who", "whom", "that", "which", "whose", "as") and relative adverbs (including when", "where" and "why"). To illustrate, the complements follows the head of a phrase. Secondly, pronoun retention which is recognized ungrammatical in English relative clauses is allowable in Chinese relative clauses. Thirdly, the relative pronoun omission is acceptable in English dative relative clause since the head of the phrase to be relativized is an object, which is not the case in Chinese. Fourthly, there appear both restrictive clause and non-restrictive relative clauses in English, however, there exists only restrictive relative clause in Chinese where 
English non-restrictive clause is usually treated as two individual sentences.

Learning difficulty of preposition pied piping in dative relative clause construction by Chinese-speaking learners can be regarded as the consequence of mother language interference (negative transfer) in that a large amount of output errors do take on strong L1 influence. Besides, many errors occur as a result of over-generalization exhibited in the relative pronoun deletion rules and preposition omission phenomenon, which can be explained in view of students' imperfect acquisition and mastery of L2 rules.

According to the interviews as complements for the questionnaire, it has been found that learners have ability to recognize their errors, but they didn't know how to avoid them by tracing the resource of these errors. With great intention to alleviate the learners' learning anxiety, teacher are suggested to make it clear that errors committed in the process of dative relative clauses reconstruction don't represent their low language proficiency or acquisitional failure. Accordingly, some practical and feasible suggestions are put forward with expectation to shed insight in the second language researches and facilitate the acquisition of dative relative clause which is one of the crucial English syntactic structures. Teachers fully exploring the learning difficulties should take an appropriate attitude toward learners' errors by offering clear guidance and detailed explanation to guide students use the dative relative clauses in the direction they designed.

\section{REFERENCES}

[1] P. Luelsdorff, Prague School (1945-1990), Beijing: Beijing University Press, 2004.

[2] P. Lacy, Markedness: Reduction and Preservation in Phonology, Cambridge University Press, 2006.

[3] R. Ellis, The Study of Second Language Acquisition, Shanghai: Shanghai Foreign Language Education Press, 1994.

[4] L. White, "Markedness and second language acquisition: The question of transfer," Studies in Second Language Acquisition, vol. 9, pp. 261-86, 1987.

[5] E. Kellerman, "Dative alternation and the analysis of data: A reply to Mazurkewich," Language Learning, vol. 35, pp. 91-106, 1985.

[6] L. White, "Second language acquisition and universal grammar," Studies in Second Language Acquisition, vol. 12, pp. 121-33, 1990.

[7] H. Riensdijk, A Case Study in Syntactic Markedness: The Binding Nature of Prepositional Phrases, Liss: the Peter de Ridder Press, 1978.

[8] I. Mazurkewich, "Dative questions and markedness," Universals of Second Language Acquisition, Rowley Massachusetts: Newbury House Publishers, Inc, 1984a, pp. 119 -131.

[9] I. Mazurkewich, "Syntactic markedness and language acquisition," Studies in Second Language Acquisition, vol. 7, pp. 15-36, 1985.
[10] M. T. Vinet, "Dialect variation and a restrictive theory of grammar: A Study of intransitive prepositions in a variety of French," Linguistics Inquiry, vol. 13, pp. 107-25, 1979.

[11] C. Allen, "Movement and deletion in old English," Linguistics Inquiry, vol. 11, pp. 261-323, 1980.

[12] K. Bardovi-Harlig, "Markedness and salience in second language acquisition," Language Learning, vol. 37, pp. 385-407, 1987.

[13] N. C. Ellis, "Usage-based and form-focused language acquisition: The Associative learning of constructions, learned attention and the limited L2 end state," Handbook of Cognitive Linguistics and Second language Acquisition, London: Routledge, 2008, pp. 372-405.

[14] F. Adani et al., "Grammatical feature dissimilarities make relative clauses easier: A comprehension study with Italian children," Lingua, vol. 9, no. 3, pp. 2148, 2010.

[15] J. C. Richards, R. Schmidt, H. Kendrick, and K. Yongkyu, Longman Dictionary of Language Teaching and Applied Linguistics, Beijing: Foreign Language Teaching and Research Press, 2005.

[16] L. Franco, "Constraint on merge," Theory and Practice in Language Studies, vol. 2, no. 1, pp. 1-5, 2012.

[17] C. Y. Ning, "Set merge and ordered merge," Modern Foreign Language, vol. 33, no. 2, pp. 111-120, 2013.

[18] C. J. C. Lin. "Effect of thematic order on the comprehension of Chinese relative clauses," Lingua, vol. 140, no. 1, pp. 180-206, 2014.

[19] S. Vasishth et al., "Processing Chinese relative clauses: Evidence for the subject-relative advantage," Plos One, vol. 8, no. 10, 2013.

[20] F. Y. Wu, K. Elsi, and A. Elaine. "Animacy effects in Chinese relative clause processing," Language \& Cognitive Processes, vol. 27, no. 10, pp. 1489- 1524, 2012.

[21] P. Skehan, A Cognitive Approach to Language Learning, Shanghai: Shanghai Foreign Language Education Press, 1998.

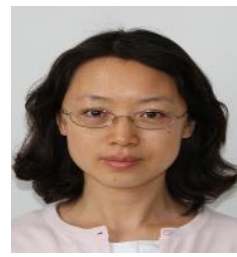

Jianhong Yang was born in March 1978, in Shanxi province, China. Her master's degree in foreign linguistics and applied linguistics was got from Foreign Studies College, Tianjin Normal University in 2008.

Since 2008, she has been working as an English teacher in the Department of Social Science and Foreign Language, Tianjin University, Renai College which is located in Boxueyuan, Tuanboxincheng, Tianjin, China. Her previous publications may be listed as follows:

J. H. Yang, "Error Analysis and Pedagogic Strategies of English Speaker's Chinese Mandarin Phonetics Learning," Language Planning, vol. 3, pp.19-20, January 2015.

J. H. Yang, "Semantic Deficiency of Chinese Fabricated Chunk in Context," Journal of Qiqihar University (Phi \& Soc Sci), vol. 7, pp. 104-106, July 2015.

J. H. Yang, "Markedness and Salience in Acquiring Preference for Preposition Stranding," Proceedings of The 2017 Northeast Asia International Symposium on Linguistics, Literature and Teaching (NALLTS). ed. Jacob A. Haskell, and Hao Bo, pp. 245-251, 2017.

Her current and previous research interests are linguistics and second language acquisition.

Associate Prof. Yang, a member of the Chinese Society of Education, got award of Tutor of First-prize Winner of NECCS (National English Competition for College Students) in 2015. 